\title{
Conservative management options for morbidly adherent placenta
}

\author{
Meena N. Satia, Animesh Gandhi, Manali P. Shilotri*
}

Department of Obstetrics and Gynecology, Seth Gordhandas Sunderdas Medical College and King Edward VII Memorial Hospital, Mumbai, Maharashtra, India

Received: 05 January 2017

Accepted: 04 February 2017

*Correspondence:

Dr. Manali P. Shilotri,

E-mail: manali.shilotri@gmail.com

Copyright: () the author(s), publisher and licensee Medip Academy. This is an open-access article distributed under the terms of the Creative Commons Attribution Non-Commercial License, which permits unrestricted non-commercial use, distribution, and reproduction in any medium, provided the original work is properly cited.

\section{ABSTRACT}

Background: Morbidly adherent placenta is still a very significant cause of obstetric hemorrhage.

Methods: A retrospective, descriptive study was undertaken over a period of one and a half year in a tertiary care hospital of all diagnosed cases of morbidly adherent placenta which were managed conservatively and the maternal and perinatal outcomes were noted. Preparation for conservative management of cases of adherent placenta in the antenatal period included informing interventional radiologists and placement of internal iliac balloon catheters just before classical caesarean section. Post-operative methotrexate was used in a few patients.

Results: 11 cases of morbidly adherent placenta diagnosed on Doppler ultrasound scan, and confirmed by MRI were identified. All patients underwent classical caesarean section. 9 patients had internal iliac balloon placement. 5 patients received methotrexate. 3 patients required obstetric hysterectomy. 1 maternal and 2 perinatal mortalities were noted.

Conclusions: Interventional radiology and methotrexate can be used to avoid peripartum hysterectomy and to optimize maternal and perinatal outcome.

Keywords: Adherent placenta, Internal iliac artery balloon placement, Methotrexate, Obstetric hysterectomy

\section{INTRODUCTION}

Obstetrics is a "bloody business". Haemorrhage still remains a leading cause of maternal mortality worldwide, despite the many medical advances. ${ }^{1}$ A rare but serious cause of obstetric haemorrhage is morbid adherence of placenta.

In most cases, after childbirth, the placenta separates itself spontaneously from the implantation site within a few minutes. Infrequently, the detachment is delayed as the placenta is unduly adherent to its attachment site. In these cases, the decidua is scanty or absent, and the physiologic line of cleavage through the decidual spongy layer, the Nitabuch's layer, is lacking. As a result, the whole or part of placenta is abnormally adherent to the deficient decidua or to the myometrium. Varying degrees of such adherence is the cause of severe haemorrhage, uterine perforation and infection that leads to significant morbidity and sometimes is fatal too.

Morbidly adherent placenta is classified according to the following characteristics:

\section{Depth of penetration of the placental villi}

- Placenta accrete- Abnormal firm adherence to the uterine wall.

- Placenta increta- Villi actually invade the myometrium.

- Placenta percreta- Villi penetrate through the myometrium to involve the uterine serosal surface or beyond. 


\section{Amount of placental surface involved}

- Total placenta accretes- All lobules abnormally adherent.

- Partial placenta accretes- Only a few lobules are adherent.

- Focal placenta accretes- All or part of a single lobule is adherent.

In the past few decades the incidence of morbidly adherent placenta has increased, paralleling the rise in the rate of caesarean sections worldwide. ${ }^{2}$ The incidence has been stated to be 1 in 2500 deliveries with advanced maternal age as an independent risk factor. ${ }^{3}$ This study was undertaken in order to develop an optimum management plan for patients with such morbidly adherent placentas. Timely antenatal diagnosis and optimum management in these cases can make a world of a difference to the mother, baby and of course the obstetrician.

\section{Aims and objectives}

To study the efficacy and compare the following conservative management options for adherent placenta:

- Preoperative internal iliac balloon placement.

- Methotrexate.

- Combination of Internal iliac balloon placement and methotrexate.

- Combination of Internal iliac balloon placement with caesarean hysterectomy.

\section{METHODS}

A retrospective, descriptive study was undertaken over a period of one and a half year in a tertiary care hospital (Seth G.S.M.C and K.E.M. Hospital) of all diagnosed cases of morbidly adherent placentas. A total of 11 patients were studied. Data was collected from the case record sheets obtained from the medical records department.

\section{Antenatal evaluation of all patients included}

- Detailed history taking: Previous obstetric history was noted in detail. Number of living issues, previous surgeries on the uterus including curettage, caesarean section, hysterotomy and myomectomy was noted.

- Confirmation of diagnosis of adherent placenta was done with Doppler ultrasound and magnetic resonance imaging (MRI).

- Opinion of interventional radiologists and urologists were taken.

- Extensive counseling of patients and development of a management plan: Patients were explained in detail their diagnosis, the potential risks in this pregnancy, possible consequences of surgery, effects on future child bearing, chances of perinatal and maternal morbidity and mortality.

Mode of delivery was planned as elective caesarean section for all patients with a written informed consent for caesarean hysterectomy if required.

Based on patient preferences and economic considerations internal iliac balloon placement was done. Intraoperative findings of placental adherence, spontaneous detachment, blood loss, uterine atony, injury to other organs dictated further management such as either leaving the placenta in situ, caesarean hysterectomy, use of methotrexate and use of postoperative internal iliac artery embolization.

The following perioperative details were noted:

- Blood loss, blood and blood products transfusions

- Need of ICU admission

- Ventilatory support

- Complications like disseminated intravascular coagulation (DIC), sepsis, acute kidney injury (AKI)

- Maternal morbidity and mortality

- Perinatal outcome (Apgar score, perinatal mortality)

- Length of hospital stay post operatively

\section{Method of internal iliac balloon placement}

Bilateral femoral arterial punctures were done and 6French vascular sheaths were inserted under local anesthesia. A 5-French cobra-shaped catheter was used to cannulate the contralateral internal iliac artery. This was exchanged for a 5.5-French occlusion balloon catheter, which was positioned with its tip in the proximal portion of the contralateral internal iliac artery, just after the common iliac artery bifurcation. After correct positioning, a test volume of dilute water-soluble contrast material was injected to inflate the occlusion balloons to the optimal size. Same volume was subsequently used to inflate the balloons, eliminating the need for additional fluoroscopic exposure during cesarean delivery. Once positioning was satisfactory, the catheters were securely taped to the skin. Balloons were inflated immediately after the baby was delivered, and the umbilical cord clamped to minimize the risk of fetal ischemia. In those who underwent hysterectomy or had the placentas delivered, the balloons were deflated just before skin closure after ensuring that haemostasis within the pelvic cavity was secured. In those in whom the placentas were retained, the balloons were left inflated.

\section{Methotrexate administration}

In patients where the placenta was kept in situ, postoperative methotrexate was given to mother after careful counseling and investigations. Investigations done 
were complete blood count (CBC), liver and renal function tests, B- hCG value, ultrasound for placental volume. Subsequent doses of methotrexate were not given if:

- Total blood count $<3000 / \mathrm{mm}^{3}$

- Polymorphonuclear leukocyte absolute count $<1500 / \mathrm{mm}^{3}$

- Platelet count $<100,000 / \mathrm{mm}^{3}$

- Elevation in baseline blood urea nitrogen, creatinine or liver enzymes

Methotrexate was given in a dose of $1 \mathrm{mg}$ per $\mathrm{kg}$ body weight, via intramuscular route on days one, three, five, seven of surgery. Folinic acid was given in dose of 0.1 mg per kg body weight, intramuscularly on days two, four, six and eight. Complete blood count, liver and renal functions were done daily. Subsequent doses were not given if the above-mentioned criteria were met.

\section{RESULTS}

A total of 11 women were studied. Average maternal age was 28.2 years. Average parity was 2.36. Association of morbidly adherent placenta with previous uterine surgery is as shown in Table 1.

Table 1: Number and type of previous surgeries associated with morbidly adherent placenta.

\begin{tabular}{|ll|}
\hline Type of surgery & $\begin{array}{l}\text { No. having adherent } \\
\text { placenta }\end{array}$ \\
\hline Previous 1 LSCS & 8 \\
\hline Previous 2 LSCS & 2 \\
\hline Previous hysterotomy & 1 \\
\hline Previous curettage & 3 \\
\hline
\end{tabular}

For pre-operative diagnosis two types of imaging modalities were used. Doppler ultrasound in all patients while 8 patients additionally underwent MRI. The types of adherent placenta diagnosed preoperatively is shown in Table 2 .

Table 2: Type of morbidly adherent placenta diagnosed pre-operatively.

\begin{tabular}{|ll|}
\hline Type of adherent placenta & No. of cases \\
\hline Placenta accreta & 2 \\
\hline Placenta increta & 3 \\
\hline Placenta percreta & 6 \\
\hline
\end{tabular}

Association with placenta praevia was found to be $100 \%$. On the basis of pre-operative counselling and intraoperative findings patients underwent different procedures for the management of adherent placenta. The distribution of patients as per the procedure they underwent is shown in Table 3.
9 patients had opted for internal iliac artery balloon placement. Of these only 7 patients successfully recovered with their uterus conserved. 2 patients underwent hysterectomy in spite of internal iliac artery balloon placement, due to uncontrollable intra-operative haemorrhage. 1 patient opted for primary caesarean hysterectomy. Thus, in all 3 patients underwent caesarean hysterectomy. Of the 8 patients in whom the placenta was left in situ, 5 patients were found to be eligible for giving systemic methotrexate.

Table 3: Procedure undertaken based on preoperative counselling and intra-operative findings.

\begin{tabular}{|ll|}
\hline Procedure & No. of cases \\
\hline $\begin{array}{l}\text { Preoperative internal iliac balloon } \\
\text { placement only }\end{array}$ & 3 \\
\hline Methotrexate postoperatively only & 1 \\
\hline $\begin{array}{l}\text { Preoperative balloon placement and } \\
\text { methotrexate }\end{array}$ & 4 \\
\hline $\begin{array}{l}\text { Preoperative balloon placement and } \\
\text { hysterectomy }\end{array}$ & 2 \\
\hline Primarily caesarean hysterectomy & 1 \\
\hline
\end{tabular}

Blood loss, on an average, was 1.4 litres in patients with pre-operative balloon catheter placement, as compared to 3 litres in patients who underwent caesarean hysterectomy. All patients needed transfusion of blood and/or blood products. Post-operative complications were as shown in Table 4.

\section{Table 4: Post-operative complications.}

\begin{tabular}{|ll|}
\hline Complication & No. of cases \\
\hline ICU requirement / ventilatory support & 2 \\
\hline Sepsis & 1 \\
\hline Methotrexate toxicity & 2 \\
\hline
\end{tabular}

There was one maternal mortality in the series and the cause was methotrexate toxicity. On an average hospital stay was 2 weeks postoperatively. As regards the neonatal outcome, 8 babies were born preterm and 3 were term babies. There were 7 neonatal intensive care unit admissions. 2 perinatal mortalities were noted. The cause was extreme prematurity in one baby and multiple severe congenital malformations in the other.

\section{DISCUSSION}

Morbidly adherent placenta is one of the most dreaded complications in obstetrics. It occurs when there is abnormal adherence of placenta to the uterine wall. This is due to a defective decidual base for the placental attachment leading to varying degrees of placental villi penetration. $73 \%$ patients in Umezurike's study had associated placenta praevia. ${ }^{4}$ However, only $31.5 \%$ patients had an associated placenta praevia in the 20 -year analysis of placenta accrete cases by $\mathrm{Wu} \mathrm{S}$ et al. ${ }^{5}$ In the 
presence of both the risk factors, previous caesarean section and placenta praevia, obstetricians must have a high index of suspicion for placenta accrete. In view of the high maternal and perinatal morbidity and mortality associated with this condition, multidisciplinary approach with an expert team of obstetrician, radiologist, anaesthetist, haematologist, blood bank facilities is essential. Early diagnosis and preparedness for the situation is very important. Antenatal Doppler ultrasonography and MRI techniques are used to establish the diagnosis and guide clinical management, leading to favourable outcomes. ${ }^{6}$

The optimal management of placenta accrete remains a topic of debate. In a study comparing the extirpative approach, consisting of forcible manual removal of the placenta, with conservative management it was found that the extirpative approach is associated with massive haemorrhage and emergency hysterectomy. Therefore, this option should be abandoned when other options are available. $^{7}$ They directly compared patients with the placentas retained and those without, and found that there appears to be a reduced amount of blood transfused and postoperative disseminated intravascular coagulation when the placenta is retained. Successful subsequent pregnancies were shown in two patients. Methotrexate has been used successfully in some cases to expedite the involution process. However, the routine use of this technique has been limited by the scarcity of scientific data, and there are few reports of serious morbidity with this technique. ${ }^{8}$

Present study showed that with the help of modern imaging techniques, new technology like interventional radiology and with drugs like methotrexate conservative management of morbidly adherent placenta is a safer option. The success rate for conservative management was $80 \%$ as hysterectomy could be avoided in 8 out of 10 patients who chose the conservative line of management. Internal iliac artery balloon placement resulted in reduction in blood loss in seven of the nine cases $(77.77 \%)$. Methotrexate was used successfully in three patients out of five either alone or combined with balloon placement $(60 \%)$. $45.45 \%$ patients had serious postnatal complications. Maternal mortality rate was 9.09 per 100 cases. The perinatal outcome was favourable in $81.81 \%$ of cases. However, the relatively scarcity of patients with this condition and the small sample of cases in this study are limitations to draw a specific protocol. Decisions regarding optimum management have to be made on an individual basis and as per the condition of the patients during surgery. Future studies may be directed at perfecting the interventional vascular techniques to further reduce the need of hysterectomy and finding new and safer drugs than methotrexate for use in this condition. Also, primary prevention of this condition has to be encouraged by reducing the ever-rising incidence of caesarean section by strict audit of the indications for the caesarean section.

\section{CONCLUSION}

All patients with morbidly adherent placenta should have pre-operative internal iliac balloon catheter placement as this has been associated with decreased blood loss during surgery, lesser complications and more chances of preserving the uterus and future fertility. Caesarean hysterectomy with internal iliac artery balloon placement would be the best option only if family is complete. Methotrexate use requires utmost caution and good patient selection.

\section{ACKNOWLEDGEMENTS}

Authors want to thank all the colleagues at the Department of Obstetrics and Gynaecology, Seth G.S.M.C and K.E.M. Hospital, Mumbai, India.

\section{Funding: No funding sources}

Conflict of interest: None declared

Ethical approval: The study was approved by the Institutional Ethics Committee, Seth G.S.M.C and K.E.M. Hospital, Mumbai, Maharashtra, India

\section{REFERENCES}

1. Cunningham FG, Leveno KJ, Bloom SL, Hauth, Rouse, Spong CY (eds.). Williams Obstetrics. 23rd edition. The United States of America: The McGraw- Hill Education; 2010.

2. Sonin A. Nonoperative treatment of placenta percreta: value of MR imaging. AJR Am J Roentgenol. 2001;177(6):1301-3.

3. Miller DA, Chollet JA, Goodwin TM. Clinical risk factors for placenta previa-placenta accrete. Am J Obstet Gynecol. 1997;177:210-4.

4. Umezurike CC, Nkwocha G. Placenta accrete in Aba, south eastern, Nigeria. Niger J Med. 2007;16(3):219-22.

5. $\mathrm{Wu} \mathrm{S}$, Kocherginsky M, Hibbard JU. Abnormal placentation: Twenty-year analysis. Am J Obstet Gynecol. 2005;192:1458.

6. Alkazaleh F, Geary M, Kingdom J, Kachura JR, Windrim R. Elective non-removal of the placenta and prophylactic uterine artery embolization postpartum as a diagnostic imaging approach for the management of placenta percreta: a case report. J Obstet Gynaecol Can. 2004;26:743-6.

7. Kayem G, Davy C, Goffinet F, Thomas C, Clement D, Cabrol D. Conservative versus extirpative management in cases of placenta accreta. Obstet Gynecol. 2004;104:531-6.

8. Butt K, Gagnon A, Delisle MF. Failure of methotrexate and internal iliac balloon catheterization to manage placenta percreta. Obstet Gynecol. 2002;99:981-2.

Cite this article as: Satia MN, Gandhi A, Shilotri MP. Conservative management options for morbidly adherent placenta. Int J Reprod Contracept Obstet Gynecol 2017;6:1057-60. 